\title{
ASPECTOS ECONÔMICOS DA CADEIA PRODUTIVA DAS BROMÉLIAS NA REGIÃO METROPOLITANA DE CURITIBA E LITORAL PARANAENSE
}

\author{
Anadalvo Juazeiro dos Santos*, Alexandre Muzy Bittencourt**, Alex Sandro Nogueira*** \\ *Eng. Florestal, Dr., Depto. de Economia Rural e Extensão da UFPR - ajsantos@floresta.ufpr.br \\ **Eng. Florestal, Mestrando em Engenharia Florestal, UFPR - alexbitt@floresta.ufpr.br \\ ***Graduando em Engenharia Florestal, UFPR, Bolsista PIBIC/CNPq - alexsandro@ufpr.br \\ Recebido para publicação: 16/03/2004 - Aceito para publicação: 04/11/2005
}

\section{Resumo}

Aspectos econômicos da cadeia produtiva das bromélias na Região Metropolitana de Curitiba e litoral paranaense. As bromélias ocorrem em todas as regiões do Brasil, com maior diversidade na região de Floresta Atlântica, entre os estados do Paraná e Bahia. Dos 54 gêneros e cerca de 2.663 espécies que constituem essa família, cerca de $40 \%$ dos gêneros e $70 \%$ das espécies ocorrem no Brasil. Do ponto de vista metodológico, foi primeiramente realizada uma pesquisa de campo, na qual foram aplicados questionários junto a extratores, produtores e comerciantes de bromélias na grande Curitiba e litoral paranaense, a fim de coletar dados econômicos. A partir desses dados, foram calculadas a Margem Bruta e o "Markup" de comercialização. Também foi construído o fluxograma que representa os diversos elos que compõem a cadeia produtiva desse produto florestal nãomadeirável. Os resultados obtidos indicam que a maior parte da lucratividade dessa cadeia é apropriada pelos intermediários, principalmente os atacadistas. Técnicas de conservação, de cultivo, assim como campanhas de conscientização com o público consumidor devem ser desenvolvidas para que ocorra um aumento da produção e conseqüentemente uma redução na extração predatória de bromélias nas áreas florestais remanescentes do estado do Paraná.

Palavras-chave: Bromélias; Margem de comercialização; Markup de comercialização; Cadeia produtiva.

\begin{abstract}
Economical aspects of the productive chain of bromeliads in the Metropolitan Area of Curitiba and the coastal region of Parana state. The bromeliads occur all along Brazilian territory, with highest diversity in the atlantic forest area, between the states of Parana and Bahia. The family is constituted of 54 "genera" and approximately 2663 species where about $70 \%$ of the "genera" and $40 \%$ of the species occur in Brazil. Questionnaires were applied to bromeliad extractors, producers and wholesalers with the objective of obtaining economical data. From these data the index of gross commercialization margins and markup of commercialization were calculated. We also built a flow concerning all the actors that compose the marketing chain. The obtained results indicate that most of the profitability of this chain is appropriate by the middlemen, mainly the wholesalers. Conservation techniques of cultivation as well as understanding campaigns with the consumers should be developed for an increase of the production and consequently a reduction in the predatory extraction of bromeliads in the forest remainders areas of the Parana state.

Keywords: Bromeliad; Margins; Markup; Productive chain.
\end{abstract}

\section{INTRODUÇÃO}

Em toda a história, as florestas tropicais têm sido valorizadas pela variedade de produtos e benefícios que dela provêm, tanto para a subsistência como para o comércio, tais como: alimentos, produtos medicinais, especiarias, resinas, gomas, látex, vida selvagem, combustível e produtos madeireiros (Santos et al., 2003).

Segundo Wickens citado por Santos et al. (2003), os produtos florestais não-madeiráveis podem ser definidos como todo o material biológico, exceto madeira roliça de usos industriais e derivados de madeira serrada (placas, painéis e polpa de madeira), que pode ser extraído do ecossistema natural ou de 
plantios manejados e que possuam mercado, significância social, cultural ou religiosa. Beer \& Modermott citados por Mok (1991) definem Produtos Florestais Não-Madeiráveis como sendo todo material biológico obtido em ecossistema florestal natural ou artificial, exceto a madeira.

A tendência atual é a aplicação da expressão "Produtos Florestais Não-Madeiráveis" utilizada pela FAO (Unasylva, 1999), que a define como relativa a produtos de origem biológica diferente de madeira, derivados de florestas nativas, áreas florestadas, reflorestadas e também provenientes de árvores isoladas de maciços florestais.

De acordo com a classificação do Instituto Brasileiro de Geografia e Estatística - IBGE (2003), que utiliza o termo "produtos de extração vegetal", estes compreendem borrachas, gomas não-elásticas, ceras, fibras, tanantes, oleaginosos, alimentícios, aromáticos e produtos e subprodutos da silvicultura.

A área de ocorrência natural das bromeliáceas estende-se desde os estados da Virgínia, Texas e Califórnia, nos EUA, até a Argentina (Reitz 1983). Segundo Leme \& Marigo (1993), a grande concentração das espécies ocorre na América do Sul, estimando-se que $40 \%$ das espécies e $73 \%$ dos gêneros ocorram no Brasil.

Costa e Fontoura citados por Rodrigues et al. (2004) afirmam que as bromélias são encontradas em diferentes condições ambientais em razão de sua facilidade de adaptação e especializações. No território brasileiro, as bromélias ocorrem principalmente na região leste, sendo $81,8 \%$ das espécies conhecidas localizadas na região da Floresta Attântica.

Entre os municípios paranaenses onde há maior ocorrência de produtores e extratores, podem-se citar Curitiba e Região Metropolitana, Guaratuba, Guaraqueçaba, Paranaguá, Morretes, Antonina, Alexandra e Tijucas do Sul. Segundo o Sr. Adilson Anacleto, técnico agrícola da Empresa Paranaense de Assistência Técnica e Extensão Rural (EMATER), existem outros municípios paranaenses também produzindo bromélias, como Londrina, Maringá e Foz do Iguaçu (comunicação pessoal). No entanto, Andrade e Demattê (1999) afirmam que os maiores produtores brasileiros estão localizados nos estados de São Paulo, Rio de Janeiro, Santa Catarina e Rio Grande do Sul.

Segundo Nadkarni (1991), as epífitas, entre elas as bromélias epífitas, possuem extrema importância e afetam muitos aspectos do ecossistema que habitam: 1) contribuem com a sustentabilidade da diversidade do ecossistema, produção e ciclagem de nutrientes; 2) proporcionam fontes de energia e nutrientes a organismos associados, como pássaros polinizadores e formigas mutualistas; 3) atuam como indicadores globais de mudanças climáticas; 4) fornecem ao homem matéria-prima para a horticultura, para fins medicinais e valor econômico; 5) criam um ambiente para estudos observacionais e experimentais sobre uma ampla gama de questões biológicas, incluindo a botânica sistemática, interação entre plantas, ecofisiologia e mecanismos de mudança evolutiva.

Nadkarni \& Matelson (1989), estudando o comportamento alimentar de aves na Costa Rica, demonstram a importância das plantas epífitas para a alimentação das aves, sendo que as bromélias, as quais acumulam água, matéria orgânica e servem de apoio a pequenos animais, servem como fonte alimentar para pelo menos 58 espécies de pássaros.

Nadkarni (1991) afirma que há um reconhecimento crescente de que a sobrevivência e manutenção de muitas espécies de epífitas estão extremamente ameaçadas, sendo duas as principais causas da redução da população de epífitas: a coleta predatória de espécies com potencial econômico para exploração comercial e a perda ou redução do hábitat das epífitas devido a atividades como a remoção e fragmentação das florestas.

Nesse contexto, o cultivo ou manejo das espécies utilizadas torna-se extremamente necessário, para que muitas delas mantenham-se preservadas em seu ambiente natural.

Assim, o cultivo de bromélias surge como opção econômica e ecologicamente viável, contribuindo para a conservação dos ecossistemas florestais naturais.

Para demonstrar essa viabilidade, o presente trabalho teve como objetivo geral analisar alguns aspectos econômicos da cadeia produtiva das bromélias na cidade de Curitiba, Região Metropolitana e Litoral Paranaense, através da elaboração do fluxograma dessa cadeia produtiva, quantificação do fluxo físico, análise das margens e "markups" de comercialização, análise do ambiente institucional e organizacional que envolve sua extração e comercialização e o levantamento dos problemas e potencialidades existentes na cadeia. 


\section{MATERIAL E MÉTODOS}

O presente estudo foi realizado na Região Metropolitana e litoral do estado do Paraná. Os dados primários foram obtidos em pesquisa de campo, através da aplicação de questionário junto a produtores, extratores e comerciantes. Foram consultadas 25 empresas (produtores e comerciantes) localizadas em Curitiba e Região Metropolitana e 16 estabelecimentos (extratores, produtores e comerciantes) no litoral do estado que comercializam plantas ornamentais.

Entre os itens abordados no questionário, ou seja, os dados primários, estão: quantidades extraídas e comercializadas por extratores e produtores, quantidades comercializadas no atacado e no varejo, preços de mercado em diferentes condições, assim como as formas de comercialização. Os dados secundários, como quantidades extraídas e consumidas em nível estadual, bem como informações quanto às exportações e importações desse produto, foram obtidos junto a instituições públicas e privadas, ligadas às atividades agroflorestais no estado.

A metodologia utilizada consistiu em:

- identificar os principais componentes da cadeia produtiva;

- elaborar seu fluxograma;

- analisar as margens e "markups" de comercialização;

- identificar os principais pontos positivos e negativos da cadeia produtiva.

\section{RESULTADOS}

Descrição dos atores que compõem a cadeia produtiva

O fluxograma dessa cadeia é bastante simples, apresentando as seguintes possibilidades desde o ecossistema florestal até o consumidor final. A figura 1 mostra essas possibilidades.

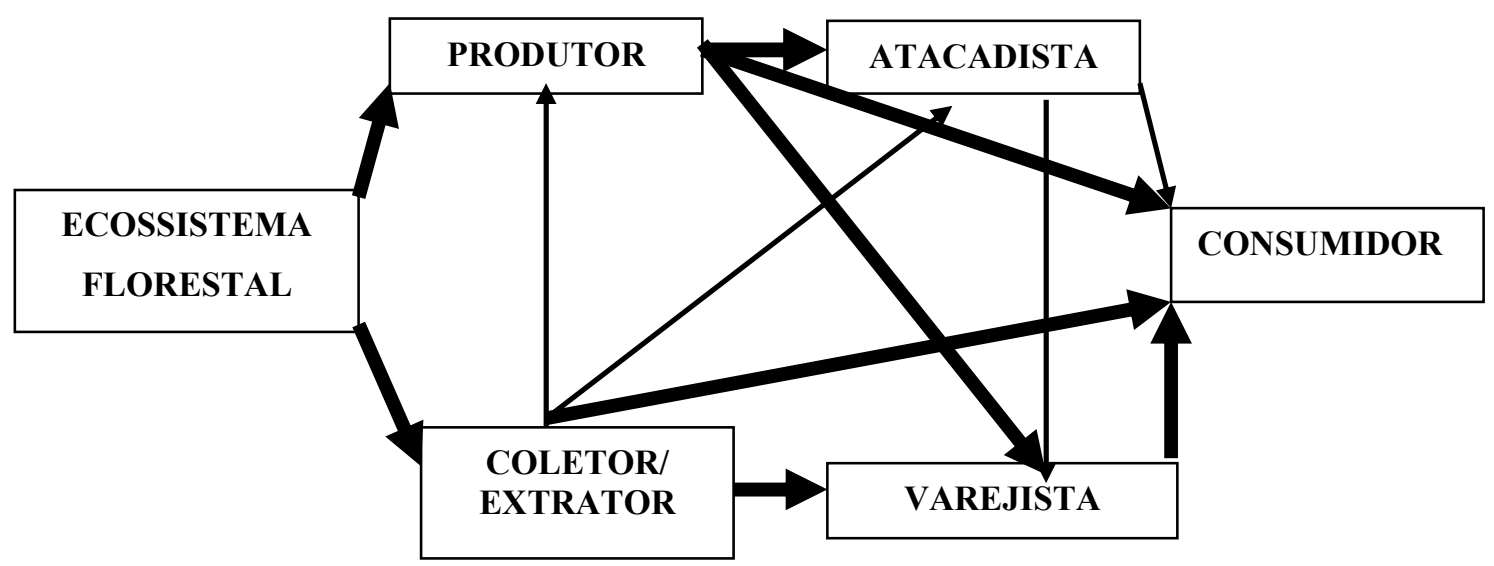

Figura 1. Fluxograma geral da cadeia produtiva das bromélias em Curitiba, Região Metropolitana e litoral paranaense.

Figure 1. General flow of productive Chain of Bromeliads in Curitiba, metropolitan area and coast of Fonte: Autores. Parana.

Para melhor entender como as relações ocorrem entre os diversos elos dessa cadeia produtiva, será descrito na seqüência cada um deles. O fluxograma acima apresenta os canais de comercialização das bromélias na área de estudo.

Os primeiros atores da cadeia são os coletores e os extratores. Os coletores são aqueles de "beira de estrada", que retiram plantas em pequena quantidade, apenas na época da floração, para incrementar a renda familiar. O segundo grupo, denominado extratores, é composto por aqueles que têm o extrativismo como única fonte de renda. Estes possuem pontos de venda definidos e retiram plantas de vários locais ao longo de todo o ano. 
Os produtores podem também se dividir em dois grupos. De larga escala, que produzem em quantidade, buscando valorizar o padrão de qualidade e a homogeneidade na produção. Nesse grupo estão os grandes produtores nacionais localizados nos estados de São Paulo, Rio de Janeiro, Rio Grande do Sul e Santa Catarina. Chegam a produzir até 50.000 plantas/mês, caso da Holambra. O produtor de pequena e média escala, grupo no qual se encontra a maioria dos estabelecimentos visitados nesta pesquisa, caracteriza-se por buscar nas bromélias uma fonte alternativa de renda. Este, além de cultiva-las, produz outras plantas ornamentais e/ou desenvolve agricultura de subsistência. Um produtor do litoral entrevistado comercializa em média 6.000 plantas/ano, podendo assim ser enquadrado como médio produtor.

Os comerciantes podem se dividir em atacadistas e varejistas. Os atacadistas verificados na pesquisa estão localizados principalmente em Curitiba e Região Metropolitana e não comercializam apenas bromélias, mas também outras plantas ornamentais, além de prestar serviço em projetos paisagísticos. Os varejistas, assim como os atacadistas, normalmente, além de bromélias, vendem outros tipos de flores ou plantas ornamentais (floriculturas).

Os consumidores podem ser tanto profissionais que trabalham com paisagismo, normalmente os maiores consumidores de bromélias, quanto as pessoas que, de uma forma geral, compram plantas ornamentais e que, nesse caso, apresentam interesse casual pelas bromélias. Normalmente, esse tipo consumidor tende a ficar com a planta apenas o tempo em que ela permanecer com flor, substituindo-a por outra posteriormente. Um grupo bem diferenciado dos demais são os colecionadores, pois geralmente são conhecedores da taxonomia da família Bromeliaceae e procuram determinadas espécies que, em geral, não são oferecidas no mercado. Dessa forma, buscam para suas coleções as plantas diretamente na natureza.

\section{Extrativismo}

A média mensal de bromélias extraídas do seu ecossistema natural e comercializadas no litoral do estado, observada na pesquisa para um vendedor de "beira-de-estrada", não ultrapassa 40 unidades/mês. No entanto, durante os meses de dezembro a março, esse número chega a triplicar. Essa atividade de extrativismo predatório pode ser facilmente observada na BR-376, na região abrangida pelos municípios de Tijucas do Sul e Guaratuba, estendendo-se até a divisa com o estado de Santa Catarina. Várias espécies dos gêneros Vriesea, Nidularium e Aechmea são vendidas, muitas vezes em vasos de xaxim também extraído ilegalmente. Constatou-se, na vila conhecida como Pedra Branca, situada às margens da BR-376, a retirada em larga escala de bromélias, especialmente da espécie Vriesea inflata (Wawra) Wawra (conhecida na região por "língua-de-fogo"), as quais eram armazenadas em um viveiro temporário e posteriormente transportadas em caminhões até Curitiba. Esses caminhões já chegavam ao local carregados com outras plantas ornamentais cultivadas, sendo as bromélias incluídas na carga.

Segundo o técnico agrícola Sr. Adilson Anacleto, da EMATER de Guaratuba, existem atualmente aproximadamente 200 produtores de bromélias no estado do Paraná, sendo que os maiores encontram-se no município de Guaratuba. Nesse município existem 40 produtores com produção anual de 40 mil plantas. Estima-se que somente no município de Guaratuba, região do litoral do Paraná, são possivelmente coletadas anualmente mais de 30 mil bromélias, sendo que nas Unidades de Conservação do estado a quantidade retirada pode atingir 150 mil plantas (comunicação pessoal).

Essa quantidade, que engloba bromélias produzidas e extraídas, não atende completamente a demanda do estado, sendo necessária a compra de bromélias provenientes de outros estados, principalmente São Paulo e Santa Catarina.

\section{Cultivo}

A cultura de tecidos é a principal forma de obtenção de plântulas em escala comercial e atender a demanda. A semeadura é utilizada apenas para selecionar matrizes a partir de híbridos ou de espécies naturais (nativas ou exóticas).

Também se pode realizar a propagação vegetativa estimulada pela morte do miolo da plantamãe. Esse método produz, em média, cerca de 20 novas plantas ao longo da vida útil da matriz (plantamãe). Já a multiplicação através da cultura de tecidos produz centenas de novas unidades.

A forma de propagação mais utilizada por produtores da Região Metropolitana de Curitiba é a partir de sementes, na qual são necessários em média 3 anos até a planta estar pronta para ser 
comercializada, no caso das espécies mais comuns. Entre estas, pode-se citar algumas espécies dos gêneros Aechmea e Neoregelia. Já espécies como Vriesea hieroglyphica E. Morren e Vriesea fosterii L. B. Smith necessitam de um período entre 4,5 e 5 anos para estarem prontas. No caso das mudas provenientes de brotações laterais ou de micropropagação, o período de amadurecimento das mudas reduz-se para cerca 1 a 2 anos e meio.

Devido ao elevado custo para se realizar a micropropagação de bromélias, muitos produtores compram plântulas de produtores maiores que já detém essa tecnologia.

No caso do produto proveniente de cultivadores e não do extrativismo as plantas são estimuladas através de hormônios a florescerem conforme as necessidades do mercado. Essa se torna uma vantagem do cultivo em relação à extração, uma vez que permite ao produtor atender a demanda continuamente.

\section{Aspectos econômicos da comercialização das bromélias na Região Metropolitana de Curitiba e litoral paranaense}

A maioria dos estabelecimentos comerciais em Curitiba compra bromélias do estado de São Paulo, sendo que 50,1\% compram do CEASA de Campinas, 19,2\% da Cooperativa de Holambra e 30,7\% das floriculturas compram bromélias produzidas no litoral do estado e na Região Metropolitana de Curitiba (RMC). Segundo comerciantes do ramo em Curitiba, o preço médio de venda ao consumidor é de $R$ \$20,00, podendo variar entre $R$ \$ 6,50 e $R$ \$ 30,00 para as bromélias de ornamentação de ambientes internos. A média de vendas de bromélias em Curitiba não ultrapassa 10 unidades/mês em pequenas floriculturas e 50 unidades/mês em grandes empresas (empresas de paisagismo).

$\mathrm{Na}$ produção de bromélias, contabilizam-se os custos de mão-de-obra, materiais (vasos, substrato, adubo, hormônios), água e energia, no caso de produção em laboratório (propagação vegetativa). Para o atacadista, soma-se a margem de lucro do produtor, o custo de transporte, embalagem e tributos. Para os produtores da Região Metropolitana de Curitiba, o custo de produção é de R\$ $0,15 /$ muda/mês, podendo variar de $\mathrm{R} \$ 3,00$ a $\mathrm{R} \$ 10,00$, dependendo do período de crescimento da espécie. Esse custo representa em média $65 \%$ do preço de venda. Produtores do litoral paranaense, devido à simplicidade e à baixa escala de produção, desconhecem ou pouco sabem sobre seus custos de produção.

As diversas regiões do estado possuem diferentes distâncias dos pólos produtores, apresentando assim diferentes preços em função das variações nas distâncias de transporte.

Para fins de comparação de preços nos diferentes estágios da cadeia (tabela 1), separaram-se as bromélias em dois grupos:

- bromélias de ambiente interno (sombra);

- bromélias de ambiente externo (pleno sol), Alcantarea imperialis Harms, sendo que, para esta espécie, classificaram-se para o levantamento de preços os tamanhos pequeno $(\mathrm{P})$, médio $(\mathrm{M})$ e grande $(\mathrm{G})$.

Tabela 1. Preço médio de venda nos diferentes segmentos da cadeia produtiva.

Table 1. Average price of sale in the different segments of the productive chain.

\begin{tabular}{lccc}
\hline \multirow{2}{*}{ Espécie } & \multicolumn{3}{c}{ Média de Preço (R\$) } \\
\cline { 2 - 4 } & Produtor & Atacado & Varejo \\
\hline Ambiente interno & 6,00 & 17,00 & 24,00 \\
A. imperialis $-\mathrm{P}$ e M & 27,50 & 69,00 & 98,50 \\
A. imperialis $-\mathrm{G}$ & 35,00 & 87,50 & 125,00 \\
\hline
\end{tabular}

Fonte: Autores.

A Alcantarea imperialis Harms (bromélia imperial) foi classificada separadamente devido a sua importância, pois foi observada em praticamente todos os estabelecimentos amostrados. Essa classificação foi necessária em virtude do grande número de espécies e da grande variedade de preços. Outra razão foi quanto à diferença na oferta de espécies de bromélias por parte dos produtores e comerciantes. Dessa forma, obtiveram-se para as bromélias os preços e margens de comercialização apresentados nas tabelas 2 e 3 . 
Tabela 2. Preços e percentuais da margem de comercialização de Alcantarea imperialis Harms (bromélia imperial) - jun/2003.

Table 2. Prices and percentile of the margin of commercialization of Alcantarea imperialis Harms (imperial bromeliad) - jun/2003.

\begin{tabular}{lcccccccc}
\hline \multirow{2}{*}{ Espécie } & \multicolumn{3}{c}{ Preços (R\$) } & \multicolumn{3}{c}{ Margem (\%) } & Part. (\%) \\
\cline { 2 - 8 } & Produtor & Atacado & Varejo & Produtor & Atacado & Varejo & Total & Produtor \\
\hline A. imperialis - P e M & 27,50 & 69,00 & 98,50 & 16,95 & 42,13 & 29,94 & 72,08 & 27,92 \\
A. imperialis - G & 35,00 & 87,50 & 125,00 & 13,60 & 42,00 & 30,00 & 72,00 & 28,00 \\
\hline Fonte: Autores & \multicolumn{1}{c}{} & & & & & & &
\end{tabular}

Tabela 3. Preços e percentuais da margem de comercialização de bromélias de ambiente interno jun/2003.

Table 3. Prices and percentile of the margin of commercialization of bromeliads of internal atmosphere - jun/2003.

\begin{tabular}{ccccccccc}
\hline \multirow{2}{*}{ Espécie } & \multicolumn{3}{c}{ Preços (R\$) } & \multicolumn{3}{c}{ Margem (\%) } & Part. (\%) \\
\cline { 2 - 9 } & Produtor & Atacado & Varejo & Produtor & Atacado & Varejo & Total & Produtor \\
\hline Ambiente interno & 6,00 & 17,00 & 24,00 & 10,00 & 45,83 & 29,17 & 75,00 & 25,00 \\
\hline
\end{tabular}

Fonte: Autores.

Observa-se, com o auxílio das tabelas 2 e 3, que o atacadista fica em média com aproximadamente $43 \%$ do preço pago pelo consumidor e que o varejista detém $30 \%$ desse valor.

A tabela 4 apresenta os seguintes preços e "markups":

Tabela 4. "Markups" de comercialização das bromélias - jun/2003.

Table 4. Bromeliads commercialization markup.

\begin{tabular}{llllllll}
\hline \multirow{2}{*}{ Tipo } & \multicolumn{3}{c}{ Preços (R\$) } & \multicolumn{3}{c}{ Markup (\%) } \\
\cline { 2 - 8 } & Produtor & Atacado & Varejo & Produtor & Atacado & Varejo & Total \\
\hline Ambiente interno & 6,00 & 17,00 & 24,00 & 40,00 & 183,33 & 41,18 & 300,00 \\
A. imperialis - P e M & 27,50 & 69,00 & 98,50 & 60,73 & 150,91 & 42,75 & 258,18 \\
A. imperialis - G & 35,00 & 87,50 & 125,00 & 48,57 & 118,57 & 42,86 & 257,14 \\
\hline
\end{tabular}

Fonte: Autores.

Analisando a tabela 4, constata-se que o atacadista torna-se então o principal responsável pela alteração de preço, aumentando em média $150 \%$ o preço pago ao produtor, enquanto que o varejista acrescenta um markup de $42 \%$. Entretanto, a maioria dos custos da cadeia produtiva fica a cargo do atacadista, sendo esses custos a embalagem, o transporte e as despesas tributárias e fiscais. Isso justificaria em parte o markup de $150 \%$. O varejista não conta com tais despesas, repassando o produto pronto ao consumidor final. Assim o consumidor final paga 300\% a mais sobre o preço inicial do produtor.

Segundo Anderson (1994), os baixos preços pagos ao extrator/produtor deve-se principalmente à dispersão espacial dos recursos naturais e das próprias populações, o que gera custos de transporte tipicamente altos, sendo a comercialização controlada por uma longa cadeia de intermediários. Conseqüentemente, as populações extrativistas são sujeitas a relações exploratórias de comercialização, nas quais os extratores recebem preços excessivamente baixos por seus produtos.

\section{Comércio interno e externo}

Apesar da produção interna, a maioria absoluta das bromélias comercializadas no estado é proveniente do estado de São Paulo (70\%).

Não foi constatada a exportação de bromélias no estado do Paraná. Outros estados, como Santa Catarina e São Paulo, estão exportando para outros estados brasileiros e também para outros países. 


\section{Aspectos legais}

Não há nenhuma lei específica de proteção às bromélias no estado do Paraná ou no Brasil. As atividades de extração, produção e comercialização de bromélias se encontram sob as mesmas leis que protegem a flora brasileira e estas estão incluídas na Lei de Crimes Ambientais (Lei n $\mathrm{n}^{\circ}$ 9.605, de 12 de fevereiro de 1998). Dentre os artigos desta lei pode-se destacar o art. 46: "Receber ou adquirir, para fins comerciais ou industriais, madeira, lenha, carvão e outros produtos de origem vegetal, sem exigir a exibição de licença do vendedor, outorgada pela autoridade competente, e sem munir-se da via que deverá acompanhar o produto até final beneficiamento. Pena - detenção, de seis meses a um ano, e multa". "Parágrafo único: Incorre nas mesmas penas quem vende, expõe à venda, tem em depósito, transporta ou guarda madeira, lenha, carvão e outros produtos de origem vegetal, sem licença válida para todo o tempo da viagem ou do armazenamento, outorgada pela autoridade competente".

De acordo com a Portaria $n^{\circ} 122-P$, de 19/03/1985, a coleta, transporte, comercialização e industrialização de plantas ornamentais, medicinais, aromáticas e tóxicas, oriundas de floresta nativa, dependem de autorização do IBAMA. As espécies mais comumente comercializadas são aquelas pertencentes principalmente às famílias Orquidaceae, Bromeliaceae, Cactaceae, Euforbiaceae, Dicksoniaceae e Araceae.

A Portaria $n^{\circ} 113$, de 29 de dezembro de 1995, tem como objetivo disciplinar a exploração das florestas primitivas e demais formas de vegetação arbórea nas regiões Sul, Sudeste, Centro-Oeste e Nordeste. Em seu artigo $1^{\circ}$, estabelece que a exploração das florestas que tenha como objetivo principal a obtenção econômica de produtos florestais somente será permitida através do manejo florestal sustentável. Ainda de acordo com essa Portaria, o manejo só deve ser permitido através do Plano de Manejo Florestal Sustentável (PMFS).

O Decreto-Presidencial $n^{\circ} 750$, de 19 de fevereiro de 1993, e sua subseqüente regulamentação, estabelece que o órgão estadual de meio ambiente competente pode autorizar a exploração de espécies nativas, de acordo com critérios técnicos estabelecidos.

A Portaria $\mathrm{n}^{\mathrm{o}} 37-\mathrm{N}$, de 3 de abril de 1992, relaciona a lista oficial de espécies da flora brasileira ameaçadas de extinção. O IBAMA, através da Divisão de Flora, tem a competência de preparar e atualizar a lista de espécies da flora brasileira ameaçadas de extinção e propor e executar medidas e programas especiais necessários à sua conservação (IBAMA, 2003). Algumas espécies de bromélias contemplam essa lista (Tabela 5).

Tabela 5. Espécies de bromélias que fazem parte da lista de espécies da flora brasileira ameaçadas de extinção.

Table 5. Species of bromeliads that are part of the list of species threatened of extinction Brazilian flora.

\begin{tabular}{lcc}
\hline \multicolumn{1}{c}{ Espécie } & Área de ocorrência natural & Categoria \\
\hline Aechmea apocalyptica Reitz & PR, SC, SP & Rara \\
Aechmea blumenavii Reitz & $\mathrm{SC}$ & Rara \\
Aechmea kleinii Reitz & $\mathrm{SC}$ & Rara \\
Aechmea pimenti-velosii Reitz & $\mathrm{SC}$ & Rara \\
Billbergia alfonsi-joannis Reitz & $\mathrm{SC}, \mathrm{ES}$ & Em perigo \\
Dyckia cabrerae Smith et Reitz & $\mathrm{SC}$ & Em perigo \\
Dyckia distachya Hassler & $\mathrm{PR}$ & Em perigo \\
Dyckia hatschbachii L.B. Smith & $\mathrm{PR}, \mathrm{SC}$ & Em perigo \\
Dyckia ibiramansis Reitz & $\mathrm{SC}$ & Em perigo \\
Fernseea itatiae (Wawra) Baker & $\mathrm{MG}, \mathrm{RJ}$ & Rara \\
Vriesea biguassuensis Reitz & $\mathrm{SC}$ & Indeterminada \\
Vriesea brusquensis Reitz & $\mathrm{SC}, \mathrm{PR}$ & Rara \\
Vriesea mulleri Mez & $\mathrm{SC}, \mathrm{PR}$ & Rara \\
Vriesea pinottii Reitz & $\mathrm{SC}, \mathrm{PR}$ & Em perigo \\
Vriesea triangularis Reitz & $\mathrm{SC}$ & Indeterminada \\
\hline
\end{tabular}

Fonte: IBAMA, 2003. 


\section{DISCUSSÃO}

O fato de ser ilegal a coleta de bromélias em seu hàbitat natural não impede que muitos comerciantes comercializem plantas dessa procedência. Há a necessidade de se intensificar a fiscalização tanto nos locais onde ocorre maior incidência desse crime ambiental quanto nos pontos de venda de plantas ornamentais. A fiscalização não ocorre periodicamente e por isso não impede a degradação, apenas minimiza. O correto seria a implantação de campanhas de conscientização a extratores e à população em geral, ao estilo das realizadas para animais silvestres. A extensão de conhecimentos técnicos e o acompanhamento da produção junto aos pequenos produtores de regiões florestais também são de extrema importância.

A boa margem de comercialização encontrada nessa pesquisa serve como incentivo para que os atuais extratores passem a cultivar as bromélias e novos produtores entrem nesse mercado. Esse aumento na produção comercial de bromélias poderá trazer vantagens tanto para o produtor, que obterá um aumento de renda, quanto para o meio ambiente, reduzindo o extrativismo predatório de algumas espécies que se encontram em perigo de extinção.

Assim, o cultivo de bromélias surge como opção econômica e ecologicamente viável, contribuindo para a conservação dos ecossistemas florestais naturais.

\section{CONCLUSÃO}

O potencial econômico e os benefícios ambientais que os Produtos Florestais Não-Madeiráveis, dentre eles as bromélias, podem proporcionar por meio da sua produção é enorme. Dessa forma, uma alternativa para reduzir a extração predatória de bromélias no litoral paranaense pode ser o incentivo da sua produção em viveiros, dando maior lucro aos produtores e preservando o remanescente de Floresta Atlântica.

Através dos dados referentes à produção paranaense de bromélias na Floresta Atlântica, chega-se à conclusão que está ocorrendo uma prática ilegal e irracional de extração que deve ser controlada. Para tanto, deve-se intensificar a fiscalização e conscientizar a população, principalmente às margens da BR376 , onde se verificou nesta pesquisa a incidência de extrativismo, sobre a possibilidade de se obter maior lucro produzindo bromélias. Para tanto, é necessário o desenvolvimento e difusão de técnicas de cultivo que indiquem ao produtor de que forma iniciar seu cultivo.

A cadeia produtiva das bromélias ainda demanda organização dos produtores, tanto econômica quanto produtiva. Sugere-se que os produtores paranaenses analisem a possibilidade de formarem cooperativas ou associações, principalmente no litoral do estado, para competir com os atuais grandes produtores de São Paulo e Santa Catarina. Assim, a formação de cooperativas ou associações de produtores proporcionaria escala e uniformidade à produção paranaense, além de, concomitantemente, tornar-se uma ferramenta para a diminuição da extração ilegal, proporcionando a organização da produção, minimizando custos, agregando valor (bromélia ecológica) e incrementando a renda familiar. Tendo em vista esses aspectos, o cultivo, além de ser economicamente mais interessante, contribui com a preservação dessas espécies.

Os incentivos governamentais, como linhas de financiamento, campanhas de conscientização e extensão de conhecimentos técnicos sobre essas plantas, tem propiciado o aumento do número de produtores, principalmente na região do litoral. Esse fato poderá reduzir muito a extração predatória de bromélias nas áreas florestais naturais remanescentes do estado do Paraná.

Esta preocupação ecológica aliada ao comprovado potencial paisagístico da espécie tem proporcionado o aumento do número de produtores paranaenses. Futuramente estes tendem a ocupar uma fatia mais significante do mercado, competindo assim, com os atuais grandes produtores de São Paulo e de outros estados.

\section{REFERÊNCIAS}

ANDERSON, A. B. Extrativismo vegetal e reservas extrativistas: limitações e oportunidades. In: O destino da floresta - reservas extrativistas e o desenvolvimento sustentável na Amazônia. Rio de Janeiro: Relume-Dumara, 1994. 276p. 
ANDRADE, F. S. A de; DEMATTÊ, M. E. S. P. Estudo sobre a produção e comercialização de bromélias nas regiões Sul e Sudeste do Brasil. Revista Brasileira de Horticultura Ornamental, Campinas, v. 5, p. 97-110, 1999.

COFFANI-NUNES; FORZZA. Inventário da Floresta Atlântica - Bromélias, 1998. Disponível em: $<$ http://www.unicamp.br> Acesso em: 13 jul. 2003.

IBAMA. Disponível em: <http://www.ibama.gov.br> Acesso em: 20 jun. 2003.

IBGE. Produção da extração vegetal e da Silvicultura. Rio de Janeiro, 2003. v. 18.

LEME, E. M. C.; MARIGO, L. C. Bromélia na natureza. Rio de Janeiro: Marigo Comunicação Visual, $1993.183 \mathrm{p}$

MENDES, J. T. Comercialização agrícola. Curitiba: Ed. Universitária, 1998. 100p.

MOK, S. T. Production and promotion of non-wood forest products.. Revue Forestière Française, Hors, Paris, Serie n6, p. 103-111, 1991. CONGRÈSS FORESTIER MONDIAL, 10., 1991, Paris.

NADKARNI, N. M. The conservation of epiphytes and their habitats: summary of a discussion at the international symposium on the biology and conservation of epiphytes. Selbyana, Sarasota, n. 13, p. 140$142,1991$.

NADKARNI, N. M; MATELSON, J. Bird use of epiphyte resources in neotropical trees. The Condor, $\mathrm{n}$. 91, p. 891-907, 1989.

REITZ, R. Bromeliáceas e a malária - bromélia endêmica. Flora Ilustrada Catarinense, Itajaí, parte 1 fasc. Brom, p. 1-518, 1983.

RODRIGUES, T. M.; PAIVA, P. D. O.; RODRIGUES, C. R.; CARVALHO, J. G.; FERREIRA, C. A.; PAIVA, R. Desenvolvimento de mudas de bromélia-imperial(Alcantarea imperialis Rarms) em diferentes substratos. Ciência e Agrotecnologia, Lavras, v. 28, n. 4, p. 757-763, 2004.

SANTOS, A. J.; HILDEBRAND, E.; PACHECO, C. H. P.; PIRES, P. T. L.; ROCHADELLI, R.. Produtos Florestais Não Madeireiros: conceituação, classificação e mercados. Floresta, Curitiba, v. 33, n. 2. p. $215-224.2003$

UNASYLVA. Towards a harmonized definition of non-wood forest products. In: Unasylva, Roma, v. 50, n. 198 , p. 3, 1999. 